\title{
Current clinical coding practices and implementation of ICD-10 in Africa: A survey of Nigerian hospitals
}

\author{
Ibrahim Taiwo Adeleke ${ }^{1,2,3, *}$, Olawole Olusegun Ajayi ${ }^{4}$, Ahmed Bolakale Jimoh ${ }^{1,3}$, \\ Abdullateef Adisa Adebisi, ${ }^{1,3}$, Sunday Akingbola Omokanye ${ }^{1,2,3}$, Mary Kehinde Jegede K, $^{1,}$ \\ ${ }^{1}$ Department of Health Information, Federal Medical Centre, Bida, Nigeria \\ ${ }^{2}$ Centre for Health \& Allied Researches, Bida, Nigeria \\ ${ }^{3}$ Health Informatics Research Initiatives in Nigeria, Bida, Nigeria \\ ${ }^{4}$ Department of Health Records, Lagos University Teaching Hospital, Idi-Araba, Nigeria

\section{Email address:} \\ ibratadeleke_aliseyin@yahoo.com (I. T. Adeleke),nhra009@yahoo.com (O. O. Ajayi), bolak58@yahoo.com (A. B. Jimoh), \\ adebisi_adisa@yahoo.com (A. A. Adebisi), sunjac4jesus@yahoo.com (S. A. Omokanye), jegexmary@gmail.com (M. K. Jegede)
}

\section{To cite this article:}

Ibrahim Taiwo Adeleke, Olawole Olusegun Ajayi, Ahmed Bolakale Jimoh, Abdullateef Adisa Adebisi, Sunday Akingbola Omokanye, Mary Kehinde Jegede. Current Clinical Coding Practices and Implementation of ICD-10 in Africa: A Survey of Nigerian Hospitals. American Journal of Health Research. Special Issue: Health Information Technology in Developing Nations: Challenges and Prospects Health Information Technology. Vol. 3, No. 1-1, 2015, pp. 38-46. doi: 10.11648/j.ajhr.s.2015030101.16

\begin{abstract}
Background: Clinical coding is an integral part of health information management (HIM) practice which provides valuable data for healthcare quality evaluation, health resource allocation, health services research, medical billing, public health programming, Case-Mix/DRG funding. The International Statistical Classification of Diseases and Related Health Problems, Tenth Revision (ICD-10) is a veritable tool for the effectiveness of clinical coding practices. Objective: This present study determined implementation levels of ICD-10 as well as ICD-10-PCS and clinical coding practices in both public and forprofit hospitals in Nigeria. Methods: We used Chi square $(\chi 2)$ and Cramer's V $(\varphi c)$ to assess the level of association between type of workplace and implementations of ICD-10 and clinical coding practices. Statistical significance was set at .05. Result: The study discovered nationwide implementation of ICD-10 $(179,88.2 \%)$ and fair adoption of its procedure counterpart (79, 38.9\%). Most hospitals in Nigeria especially, for-profit facilities (3, 100\%) and tertiary healthcare settings (148, 93.1\%) employed HIM professionals $(214,91.5 \%)$ to manage their clinical coding processes. Conversely, the study observed that challenges confronting clinical coding processes were enormous. Notable among these were absence of automation (70, $34.5 \%)$, lack of political will $(51,48.1 \%)$, inadequate clinical coders $(153,74.4 \%)$ and suboptimal documentation $(186,91.6)$. Suggestions to improve clinical coding practices ranges from continuing professional coding education (33, 10.3\%) to initiation of Nigerian's modification of ICD such that ICD-10 will become ICD-10-NGM (1, 0.3\%). Conclusion: Most healthcare systems in Nigeria have implemented ICD-10 for coding and classification of diagnoses and procedures and the process is being managed by the right workforce (i.e. HIM professionals) which reassures effectiveness. However, lack of political will, inadequate and unmotivated workforce and suboptimal clinical documentation were among challenges confronting the practice in Nigeria. Therefore, this study suggests advocacy and coding education with a view to modifying the orientation of all stakeholders and to sensitize relevant authorities on the benefits of clinical coding practices in order to maximize its outcome and in effect, improve public health in the country.
\end{abstract}

Keywords: Automated Coding, Clinical Coding, Clinical Documentation, Data Quality, Discharge Summary, Health Information Technology, Health Information Management Professionals, ICD-10

\section{Introduction}

The study of diseases and the international classification of diseases (ICD) began in the $16^{\text {th }}$ century with the work of John Graunt on the London Bills of Mortality [1]. Its main purpose was to permit systematic recording, analysis, interpretation and comparison of mortality and morbidity data collected in different countries or areas and at different times. The ICD is traditionally reviewed every ten years and in 1989 , the International Conference on the $10^{\text {th }}$ revision 
agreed that it would not be feasible to hold revision conferences more frequently than every ten years [2]. In the same way, the ICD-10-Procedure Coding Systems was developed for coding of surgical operations and other procedures [3]. It has multi-axial structure and detail definitions of terminology which permits precise specification of procedures and enhances the ability of clinical coders in determining accurate procedure codes with minimal efforts [3].

Clinical coding and classification processes transform natural language descriptions in clinical text into coded data that can be subsequently used for clinical care, research, and other purposes [4]. The code is measured in detail in order to accurately describe diagnoses (i.e. what is wrong with the patient) and the procedures performed to test or correct these diagnoses. Because medicine is not an exact science, codes were developed to identify all reasons for seeking healthcare [5]. Although, coding was perceived to have potentially jeopardized doctor-patient relationship and was said to be a difficult and often tedious activity, it has been established that it has no equal in health data management and as such, healthcare systems at large [6-8]. Codes also allow insurance providers to map equivalences across different healthcare providers who may use different terminologies or abbreviations in claim forms [9].

A universal veritable tool that facilitates good clinical coding is the discharge summary (or clinical résumé) which is a concise recapitulation of the patient's course in the hospital [10]. Though it was reported [11-13] not to be written always or vital part omitted when written, it provides the information to support clinical documentation review process and clinical coding. While it is true that clinical coders' variability in coding may be related to the inadequacy of their training and experience, physician's documentation can impede accurate interpretation of medical charts by the coders [14]. Good clinical documentation enhances clinical coding as it ensures the availability of reliable information for the production of quality and accurate data for quality patient care [15-16]. Conversely, poor documentation undermines analyses-based chart review, affects clinical coding processes and can reduce the quality of care [17]. Clinical documentations in computer-based records are found to be more complete and appropriate for clinical decisions than those in paper-based records [18]. Likewise, automated coding and classification encompasses a variety of computerbased approaches, that are faster, reduce error rates, and are more efficient and accurate [4, 19-21]. Similarly, improvement in clinical documentation will be necessary to ensure complete automated coding [22].

\subsection{Aim of the Study}

Clinical coding is an integral part of health information management practice which is essential to quality healthcare services and research. Research outcomes have shown that implementation of ICD-10 did not significantly transform coding practices especially for common conditions [23-24] and that only $52 \%$ of inpatients facilities employed clinical coders [25]. However, other researchers have established that coding competency is extremely important to healthcare and information systems [26] and that disease classifications have globally helped healthcare stakeholders to navigate, understand, and compare healthcare systems and services [24]. This current study from Nigeria sought to establish implementation levels of ICD-10 as well as ICD-10-PCS and clinical coding practices in both public and for-profit hospitals in Nigeria.

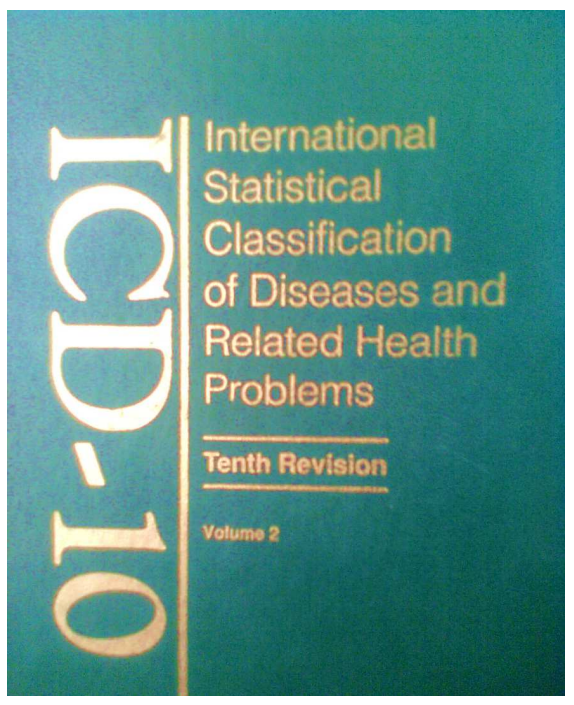

Fig 1. Front cover of ICD-10 Vol II

\section{Methods}

\subsection{Background to the Study Area}

This nationwide study on clinical coding was conducted at the $36^{\text {th }}$ and $37^{\text {th }}$ annual national conferences of Health Information Managers' Association of Nigeria (HIMAN) held in Lagos and Cross Rivers States in 2012 and 2013 respectively. It was also conducted at the $1^{\text {st }}$ National continuing education program organized by Health Records Officers' Registration of Nigeria (HRORBN) at Nostalgia Hotels and Resorts, Lokoja in April 2013.

\subsection{Study Population}

HIM professionals in Nigeria conventionally manage data and information in healthcare systems. All HIM professionals who participated at the three conferences were eligible to participate in the study.

\subsection{Study Design}

This is a cross-sectional survey of healthcare facilities in Nigeria on the implementations of ICD-10 and clinical coding practices.

\subsection{Data Collection Tools}

A semi-structured questionnaire on the subject was administered on the conference attendees who so agreed to participate in the study. 


\subsection{Sampling Techniques and Sampling Size}

A convenience sample, randomly selected from the conference attendees was recruited for the study. A total of 320 HIM professionals gave their consent for participation.

\subsection{Data Analysis and Management}

The Statistical Software (SPSS 16.0 for window) was used to analyze the data. Chi square and Cramer's $\mathrm{V}$ were computed for the nominal by nominal variables and $p$-value for statistical significance was set at .05 . Simple percentage was also computed for succinct descriptions.

\subsection{Ethics}

Informed consent was clearly worded on the page before the questionnaire to obtain participants' consent. Permission to administer the instrument was granted by the National President of Health Information Managers' Association of Nigeria (HIMAN) and the Registrar/CEO of Health Records Officers' Registration of Nigeria (HRORBN) at respective gatherings.

\section{Results}

\subsection{Participants' Demography}

A total of three hundred and twenty conference attendees participated in this study, $52.0 \%$ of whom were female and they mostly $(175,54.7 \%)$ worked with tertiary healthcare settings. A greater portion $(176,55 \%)$ of these participants partake in clinical coding processes with less than a quarter $(78,24.4 \%)$ having benefitted from special coding education program.

\subsection{Current Clinical Coding Practices}

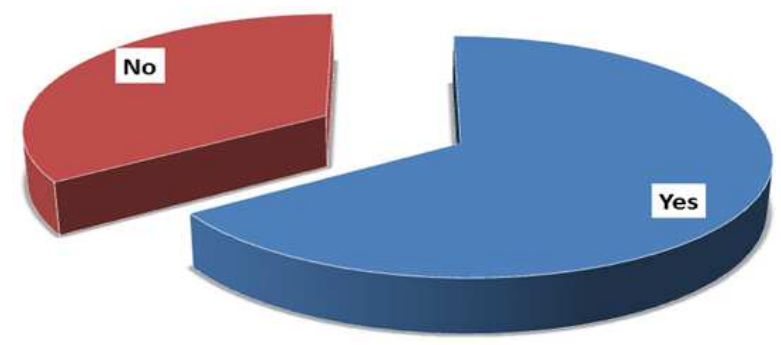

Fig 2. Coding of discharged records in participants' institutions

More than two-third $(203,67.2 \%)$ of the participants worked in settings where clinical coding is carried out on discharged patient health records (See Fig 2). A greater portion $(166,81.8 \%)$ of settings where clinical coding takes place, codes all discharged health records and mostly (131, $64.5 \%$ ) code principal diagnosis, secondary and complications. As depicted in Fig 3, such settings were predominantly $(174,85.7 \%)$ paper-based systems (i.e. manual clinical coding). Donak Software appears the most (5, $33.3 \%$ ) adopted in the few places $(15,7.4 \%)$ where automated coding is in operation.

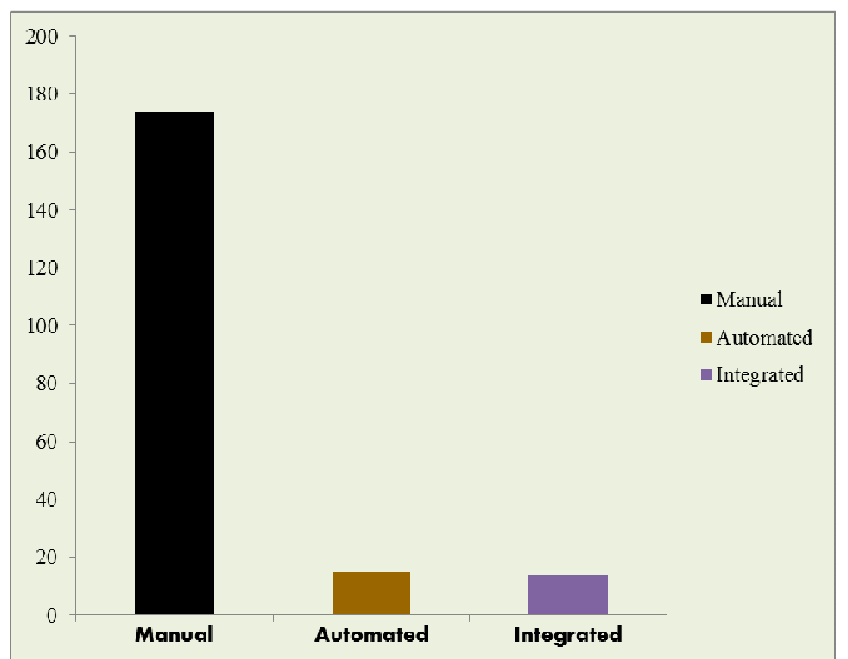

Fig 3. Clinical coding systems

\subsection{Reasons for Non-Coding of Discharged Patients' Health Records}

Various reasons adduced for not carrying out clinical coding in some Nigerian healthcare facilities as contained in Table 1 include lack of political will $(51,48.1 \%)$, expensive code books $(20,18.9 \%)$ and insufficient trainers in clinical coding $(10,9.4 \%)$.

Table 1. Reasons for non-coding of discharged records

\begin{tabular}{lll}
\hline Reasons & Yes & Percentage (\%) \\
\hline $\mathrm{N}=106$ & & \\
Lack of political will & 51 & 48.1 \\
Funding problems & 37 & 34.9 \\
Inadequate number of clinical coders & 28 & 26.4 \\
Expensive code books & 20 & 18.9 \\
Low inpatient admission rates & 19 & 17.9 \\
Not applicable to setting & 15 & 14.2 \\
Lack of awareness & 12 & 11.3 \\
Insufficient trainers in clinical coding & 10 & 9.4 \\
Inexperienced clinical coders & 8 & 7.5 \\
Others & 7 & 6.6 \\
\hline
\end{tabular}

3.4. Classification Code Books for Diagnoses and Procedures

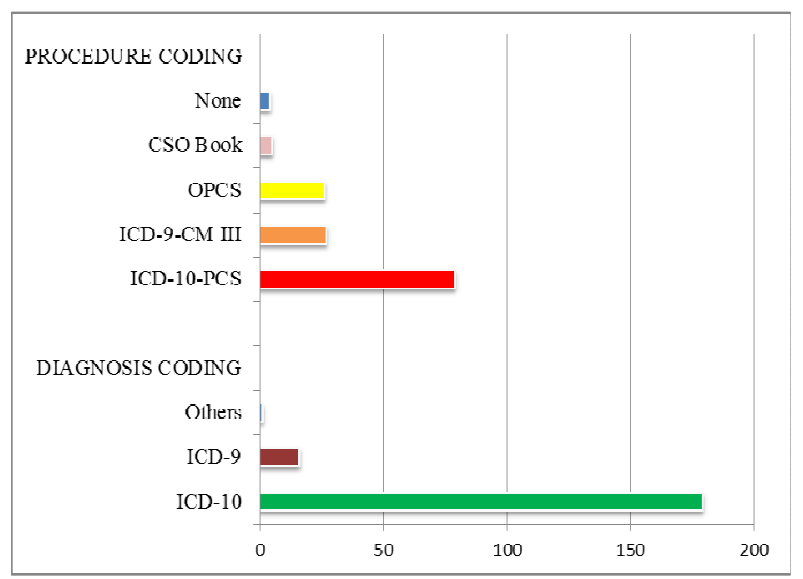

Fig 4. Code books for diagnoses and procedures 
Fig 4 demonstrates different classification texts used for classification of diagnoses and procedures. In most healthcare settings in Nigeria, ICD-10 $(179,88.2 \%)$ is in use for disease classification and ICD-10-PCS $(79,38.9 \%)$ for coding of procedures. It is noteworthy that a few $(4,2.0 \%)$ of the settings did not have any code book in place for the classification of procedures.

\subsection{Job Titles of Clinical Coders}

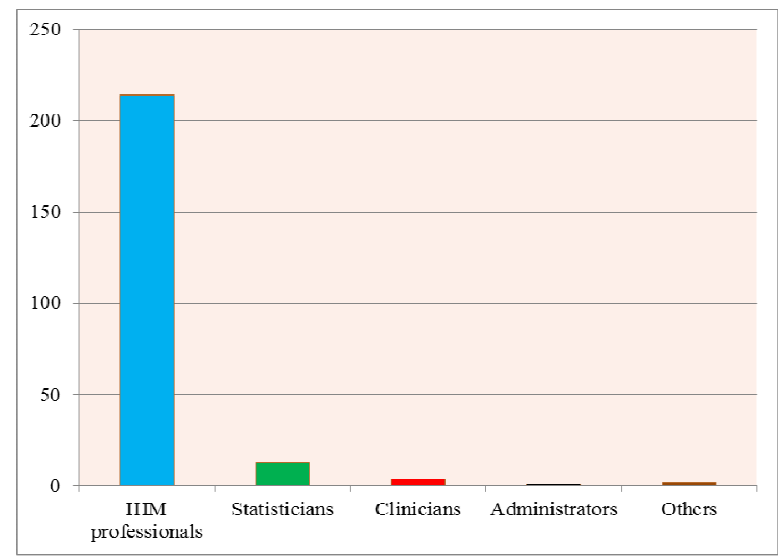

Fig 5. Job titles of clinical coders

Most participants $(234,73.1 \%)$ including those from settings where clinical coding is not in operation reported that the majority $(214,91.5 \%)$ of clinical coders in Nigeria are HIM professionals (Fig 5). More than two-third (139, $68.5 \%$ ) of the settings were reported to have between one and three clinical coders, most $(153,74.4 \%)$ of whom spent more than four hours on clinical coding per day as they equally attend to other HIM chores. These other duties include data entry $(55,27.1 \%)$, general HIM duties (50, 24.6\%), documentation $(43,21.2 \%)$, quality assurance $(27,13.3 \%)$ and data analysis $(25,12.3 \%)$.

\subsection{Challenges to Clinical Coding Practice}

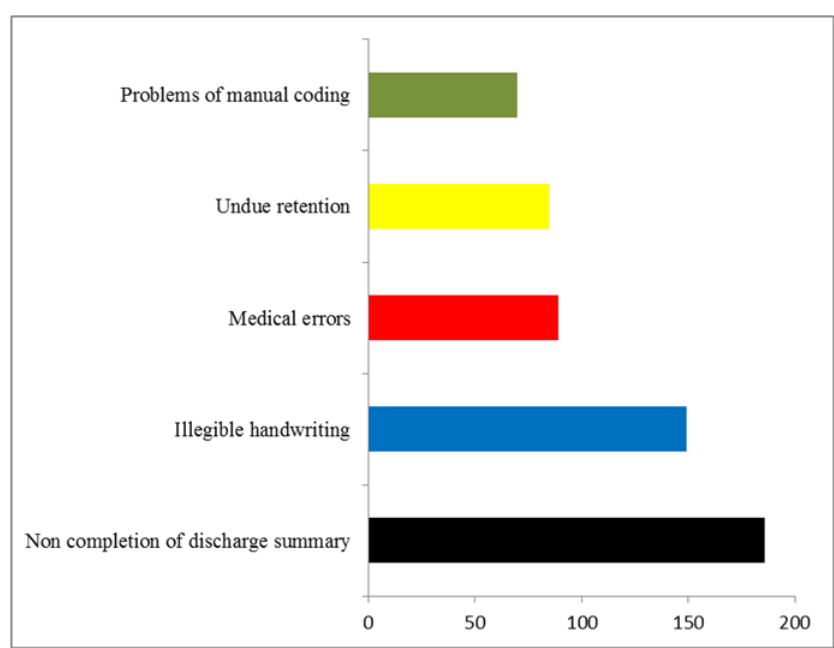

Fig 6. Challenges to clinical coding practice

From Fig 6 above, non-completion of discharge summary appears the most reported $(186,91.6 \%)$ challenge to clinical coding while problems of illegible handwriting of clinicians was reported next $(148,72.9 \%)$.

\subsection{Type of Healthcare Facility and Clinical Coding Practices}

Table 2 below shows that type of workplace is associated with clinical coding practices. For instance, private or forprofit healthcare facilities were reported to have good disposition especially towards coding automation (100\%) and professionalism $(100 \%)$ except that they were poor in the area of special coding education $(0 \%)$. This was followed by tertiary healthcare facilities with considerably high percentages in all coding aspects except in coding automation $(8.8 \%)$ and inadequacy in clinical coders $(13.5 \%)$.

Table 2. Clinical coding practices across healthcare facilities

\begin{tabular}{|c|c|c|c|c|c|c|c|}
\hline Workplace type & Yes & No & \% coding & $\chi^{2}$ & $\varphi c$ & df & $p$-value \\
\hline \multicolumn{8}{|l|}{ Code discharged records } \\
\hline Tertiary & 154 & 20 & 88.5 & 2.028 & .563 & 20 & .000 \\
\hline Secondary & 34 & 46 & 42.5 & & & & \\
\hline Primary & 3 & 24 & 11.1 & & & & \\
\hline Private hospital & 3 & 1 & 75.0 & & & & \\
\hline Other healthcare facilities & 7 & 15 & 31.8 & & & & \\
\hline \multicolumn{8}{|l|}{ Automated coding } \\
\hline Secondary & 0 & 36 & 0 & & & & \\
\hline Primary & 0 & 5 & 0 & & & & \\
\hline Private hospital & 3 & 0 & 100 & & & & \\
\hline Other healthcare facilities & 0 & 9 & 0 & & & & \\
\hline \multicolumn{8}{|c|}{ HIM professionals as clinical coders } \\
\hline Tertiary & 148 & 11 & 93.1 & 1.181 & .248 & 60 & .000 \\
\hline Secondary & 44 & 4 & 91.7 & & & & \\
\hline Private hospital & 3 & 0 & 100 & & & & \\
\hline Other healthcare facilities & 13 & 2 & 86.7 & & & & \\
\hline \multicolumn{8}{|c|}{ Acquired special coding education } \\
\hline Tertiary & 56 & 90 & 38.4 & 59.885 & .250 & 30 & .001 \\
\hline Secondary & 12 & 46 & 20.7 & & & & \\
\hline Primary & 4 & 8 & 33.3 & & & & \\
\hline
\end{tabular}




\begin{tabular}{|c|c|c|c|c|c|c|c|}
\hline Workplace type & Yes & No & \% coding & $\chi^{2}$ & $\varphi \mathrm{c}$ & df & $p$-value \\
\hline Private hospital & 0 & 3 & 0 & & & & \\
\hline Other healthcare facilities & 5 & 6 & 45.5 & & & & \\
\hline \multicolumn{8}{|c|}{ Adequate number of clinical coders } \\
\hline Tertiary & 21 & 134 & 13.5 & 1.294 & .367 & 30 & .000 \\
\hline Secondary & 7 & 39 & 15.2 & & & & \\
\hline Primary & 2 & 6 & 25.0 & & & & \\
\hline Private hospital & 3 & 1 & 75.0 & & & & \\
\hline Other healthcare facilities & 2 & 8 & 20.0 & & & & \\
\hline
\end{tabular}

Legend:

$\chi^{2}-$ Chi square

$\varphi c-$ Cramer's V

df - degree of freedom

\subsection{Recommendations for Improving Clinical Coding Practices}

Participants proffered suggestive ways to improve clinical coding practices in Nigeria. Major suggestions include continuing professional coding education (33. 10.3\%), enforcing clinical coding at all healthcare establishments (23, $7.6 \%$ ) and provision of clinical coding facilities (10, 3.1\%). It is good to note that a participant $(1,0.3 \%)$ opined that Nigeria is due to have country modification of ICD such that ICD-10 will turn ICD-10-NGM.

Table 3. Recommendations for clinical coding improvement

\begin{tabular}{|c|c|c|}
\hline Recommendations & Frequency & Percentage \\
\hline $\begin{array}{l}\text { Continuing professional education on } \\
\text { clinical coding }\end{array}$ & 33 & 10.3 \\
\hline $\begin{array}{l}\text { Enforce compulsory clinical coding } \\
\text { practice }\end{array}$ & 23 & 7.6 \\
\hline Provision of coding facilities & 10 & 3.1 \\
\hline Professionalise clinical coding process & 5 & 1.6 \\
\hline $\begin{array}{l}\text { Enforce unified automated coding (via } \\
\text { EHR) }\end{array}$ & 5 & 1.6 \\
\hline $\begin{array}{l}\text { Conduct specific survey of training } \\
\text { institutions }\end{array}$ & 4 & 1.3 \\
\hline Employment of more HIM professionals & 3 & 0.9 \\
\hline $\begin{array}{l}\text { Reorientation of clinicians about discharge } \\
\text { summary }\end{array}$ & 2 & 0.6 \\
\hline Attitudinal change & 1 & 0.3 \\
\hline $\begin{array}{l}\text { Communicate research outcomes on } \\
\text { clinical coding to participants }\end{array}$ & 1 & 0.3 \\
\hline $\begin{array}{l}\text { Initiate Nigeria modifications of ICD e.g. } \\
\text { ICD-10-NG }\end{array}$ & 1 & 0.3 \\
\hline $\begin{array}{l}\text { Create proper awareness on ICD and } \\
\text { clinical coding }\end{array}$ & 1 & 0.3 \\
\hline Good will & 1 & 0.3 \\
\hline
\end{tabular}

\section{Discussion}

The tenth revision of the international classification of diseases (ICD-10) has been adjudged [27] as having the most remarkable impact on disease classification in over fifty years of practice. Its implementation reflects current medical knowledge, enables code expansion and provides more details about common ailments [28]. ICD-10 also enables a more detailed description of the location on the patient's body such that it is capable of decreasing medical fraud and abuse. For instance, by reducing the ability to repeatedly report the same procedure on the same side of the body [29].
Despite the two decades of its publication and the plans to steer up the $11^{\text {th }}$ revision by 2016 [24], some developed nations especially, the United States of America has not actually implemented the ICD-10 as the country sets to implement it by October 1, 2015 [30]. On the other hand, it is evident from our study that clinical coding practices and especially, implementation of ICD-10 and its procedure counterpart, ICD-10-PCS is no longer a mirage in Nigeria as $88 \%$ of healthcare settings in Nigeria practice full diagnoses coding with ICD-10 and $39 \%$ carry out procedure coding using ICD-10-PCS. This further supports a study [11] from Nigeria that most $(81 \%)$ of the discharged patients' folders reviewed in the study were coded. The preponderance of paper-based health records systems [31-32] has multiplying effects on the practice of clinical coding seeing that as low as $7 \%$ operate automated coding. This might have informed the low $(39 \%)$ utilization of ICD-PCS which it is more functional with automation.

Studies have shown that automated coding has improved data processing, greatly increased comparability with other countries [33] and has improved coding productivity and revenue [34]. Automated coding is faster and has the potentials to increase coding consistency and productivity and has improved overall coding accuracy. Good documentation exists in electronic records and is of better quality than those held in paper-based records [35-39]. Just as this present study suggests enforcement of unified automated coding, two studies [40-41] of Nigerian HIM professionals on KAP of clinical coding reveal that the vast majority of the participants agreed that automated coding system is more efficient than manual coding. In other Nigerian healthcare settings where clinical coding practice is not in place and the implementation of ICD-10 has not come to fruition, participants adduced lack of political will as the major (48\%) impediment. Other notable reasons were inadequacy in clinical coding workforce (26\%) and insufficient trainers in clinical coding $(9 \%)$. Without political will from relevant authorities in healthcare, adoption of ICD10 and successful implementation of clinical coding practices like every other health technologies and innovations may not see the light of the day. Rao et al [42] recognized political will as an essential ingredient needed to revitalize vital registration and statistics which must be placed high on the developmental agenda of any country. Basically, participants' workplace was associated with type of their practice of 
clinical coding. Private or for-profit healthcare facilities had good disposition (100\%) towards coding automation and coding professionalism, but did not give priority to special coding education. Similarly, clinical coding practices at tertiary healthcare facilities were considerably efficient except that automation (8.8\%) and adequacy of clinical coders $(13.5 \%)$ were lacking. These findings agree with the report by Cunningham et al [43] where coding specificity of a hospital stood it out in the comity of healthcare industry.

Challenges to clinical coding practices in Nigeria are enormous ranging from problems of manual coding (35\%), undue retention $(42 \%)$, medical errors (44\%), illegible handwriting $(73 \%)$ and non-completion of discharge summary $(92 \%)$. The two major challenges border on clinical documentation and health data quality as it affects clinical coding. The quality of health records and clinical documentation directly affects the quality of clinical coding [43]. Cunningham et al [43] also reported insufficient information for specific code assignment. Similarly, documentation issues have been of primary concern for coding quality [44] and it has been suboptimal in developing nations such as Nigeria [11] where discharge summary is reported to be grossly underutilized. Bad clinical documentation makes information inaccessible [45] and causes coding errors [46]. In effects, clinical coding errors portend inefficient operation and it inhibits financial management of hospitals and most times, potentially lead to inaccurate hospital morbidity statistics and mortality data [47]. Since ICD-10 requires a level of specificity lacking in previous revisions, authorities concerned have been charged [48] to ensure physicians as well as other contributors to patients' health records, have the right tools at hand in order to document effectively.

The World Health Organization classified clinical coding as a major and exclusive responsibility of HIM professionals and specified that as clinical coders; they require knowledge of medical terminology, legal aspects of health information, health data standards, and computer- and/or paper-based data management [49]. Our study shows that nearly all (92\%) clinical coders in Nigeria are HIM professionals with less than a quarter $(24 \%)$ of them specially trained in clinical coding. More than two-third $(69 \%)$ of the settings (mostly tertiary - 55\%) have one to three clinical coders in their employment. The majority (74\%) of these coders spent more than four hours on clinical coding duties as they had to attend to other duties of managing health information such as data entry $(27 \%)$, documentation $(21 \%)$ and quality assurance $(13 \%)$. Our findings coincide with other studies that clinical coders do engage in other duties [43]. Even, managers of clinical coding units recommended that engaging in a variety of role behaviours will improve clinical coding practice [47]. As it is obtainable in developed nations [43], the Nigerian healthcare systems need special education in clinical coding as advanced by researchers [47-48] in order to have a thorough understanding of ICD-10 and the fact that ICD-10 would require more time for clinical coding processes [50]. Participants in this study suggested ways to improve clinical coding practices in Nigeria. These include continuing professional coding education (10\%), enforcing the implementation of clinical coding in all healthcare establishments (8\%), provision of clinical coding facilities (3\%) and an individual participant suggested a Nigerian modification of ICD such that the country may have ICD-10NGM.

\subsection{Study Limitations}

Clinical coding practices in the country look wholesome and encouraging according to this study. However, the study lacks the impetus to apportion credit to the practice in Nigeria as the study has not been designed to determine the quality of the practice in terms of accuracy, its outcome in terms of data integrity and its benefits in terms of utilization for reimbursement, research, planning and international and local reporting. Therefore, future studies from the country should focus on coding accuracy, reliability and meaningful use.

\section{Conclusion}

Most healthcare facilities in Nigeria have implemented ICD-10 in the classification of diseases and a good number of them have adopted the ICD-10-PCS for coding and classification of procedures. For-profit organizations (private hospitals) and tertiary healthcare facilities hold the drive for good clinical coding practices and are better equipped for such practices. Furthermore, the right workforce (i.e. HIM professionals) manage clinical coding processes in the Nigerian healthcare systems, which holds promises that the process is effective and reliable for morbidity statistics and mortality data for local and international consumption. Nonetheless, clinical coding practice is being constrained by unwholesome political will, inadequate and unmotivated workforce and suboptimal clinical documentation due to preponderance of paper-based health records system. The attendant challenges may pose threats to the practice of clinical coding in Nigeria therefore; efforts should be geared towards appreciation of the practice and maximization of its outcome with a view to improving public health.

\section{Recommendations}

i There should be continuing professional coding education especially for HIM professionals who participate in clinical coding. This action is the reserve of the regulatory body for HIM profession in Nigeria (HRORBN) and respective heads of healthcare institutions.

ii There is the need to strengthen clinical coding units in Nigerian hospitals by appropriate postings of HIM professionals both in quantity and quality. This is the reserve of respective heads of health information departments.

iii Provision of adequate coding tools and automation of clinical coding process is of paramount importance. 
iv All healthcare providers (especially, doctors and nurses who are the major contributors to patients' health records) in Nigeria require continuing professional education and reorientation on clinical documentation practices in order to ensure good data quality.

\section{Acknowledgement}

The authors honour Mr. Danjuma Aliyu of Ahmadu Bello University Teaching Hospital, Zaria Nigeria for his comments on the final manuscript. We also thank the three hundred and twenty HIM professionals who participated in the study.

\section{Appendix I}

Table 4. Workplace distribution by geographical areas

\begin{tabular}{|c|c|c|c|c|c|c|c|c|}
\hline Workplace type & $N=320$ & NW & SW & $\mathrm{NC}$ & SS & NE & SE & NR \\
\hline Tertiary & 175 & 15 & 35 & 20 & 25 & 16 & 15 & 49 \\
\hline Secondary & 81 & 3 & 22 & 12 & 14 & 3 & 3 & 24 \\
\hline Primary & 28 & 1 & 11 & 1 & 3 & 0 & 0 & 12 \\
\hline Training institution & 13 & 3 & 1 & 1 & 3 & 9 & 1 & 4 \\
\hline $\begin{array}{l}\text { University/ } \\
\text { polytechnic clinics }\end{array}$ & 6 & 0 & 0 & 1 & 1 & 1 & 0 & 3 \\
\hline Private hospital & 5 & 1 & 3 & 0 & 0 & 0 & 0 & 1 \\
\hline $\begin{array}{l}\text { State hospital } \\
\text { management board }\end{array}$ & 3 & 0 & 0 & 1 & 0 & 0 & 1 & 1 \\
\hline Military hospital & 2 & 0 & 1 & 0 & 0 & 0 & 0 & 1 \\
\hline $\begin{array}{l}\text { Planning } \\
\text { commission }\end{array}$ & 1 & 0 & 0 & 0 & 0 & 0 & 1 & 0 \\
\hline Others & 3 & 0 & 1 & 0 & 0 & 0 & 0 & 2 \\
\hline Not indicated & 3 & 0 & 0 & 0 & 0 & 0 & 0 & 3 \\
\hline NW - North-west & & \multicolumn{7}{|c|}{ NE - North-east } \\
\hline SW - South-west & & \multicolumn{7}{|c|}{ SE - South-east } \\
\hline NC - North-central & & \multicolumn{7}{|c|}{ NR - No response } \\
\hline SS - South-south & & & & & & & & \\
\hline
\end{tabular}

\section{References}

[1] World Health Organization. International Statistical Classification of Diseases and Related Health Problems, Tenth Revision. Volume II. World Health Organization (Geneva: 1993).

[2] World Health Organization. International Classification of Diseases. Available www.who.int/Intenational_Classification_of Diseases.htm Accessed on: $22^{\text {nd }}$ December 2011

[3] R. F. Averill, R. L. Mullin, B. A. Steinback, et al. Development of the ICD-10-Procedure Coding System. Centres for Medicare and Medicaid Services 2009. Contract Number: 90-1138, 91-22300, 500-95-0005 and HHSM-5002004-00011C to 3M Health Information Systems Research Report pp24.

[4] M. H. Stanfill, M. Williams, S. H. Fenton, et al. A systematic literature review of automated clinical coding and classification systems. J Am Med Inform Assoc. 2010; 17(6):646-651.
[5] American Health Information Management Association. Clinical Coding. Available at www.ahima.org/coding Accessed on $5^{\text {th }}$ June 2012.

[6] S. D. Lusignan, S. E. Wells, N. J. Hague, et al. Managers see the problems associated with coding clinical data as a technical issue while clinicians also see cultural barriers. Methods Inf Med 2003; 42:416-22.

[7] S. E. Campbell, M. K. Campbell, J. M. Grimshaw, et al. A systematic review of discharge coding accuracy. Journal of Public Health Medicine. 2001;23(3): 205-211.

[8] S. D. Lusignan. The barriers to clinical coding in general practice: a literature review. informatics for health and social care. 2005;30(2):89-97. doi:10.1080/14639230500298651.

[9] CHKS Ltd. Clinical Coding. Available at www.chks.co.uk/index.php\%3Fid\%3D33. Accessed on $30^{\text {th }}$ July 2012.

[10] E. K. Huffman. Medical Record Management. $9^{\text {th }}$ Edition as revised by AHIMA. Physicians' Records Company Berwyn, Illinois; 1990

[11] I. T. Adeleke, A. O. Adekanye, K. A. Onawola, et al. Data quality assessment in healthcare: a 365-day chart review of inpatients' health records at a Nigeria tertiary hospital. J Am Med Inform Assoc 2012; 19:1039-1042 doi: 10.1136/amiajnl2012-00823.

[12] A. J. H. Kind, M. A. Smith. Documentation of mandated discharge summary components in transitions from acute to sub-acute care. In: Henriksen K, Battles JB, Keyes MA, et al, eds. Advances in patient safety: new directions and alternative approaches (Vol. 2: Culture and Redesign). Rockville (MD): Agency for Healthcare Research and Quality (US), 2008.

[13] B. J. Petterson. Content and structure of the health record. In: Health Information Management Technology: An Applied Approach. (Second Edition) Johns ML (Ed) (American Health Information Management Association Chicago Illinois 2007 p47-112).

[14] L. So, C. A. Beck, S. Brien, et al. Chart documentation quality and its relationship to the validity of administrative data discharge records. Health Informatics Journal. 2010;16(2):101-113.

[15] W. R. Hersh. Stimulus to define informatics and health information technology, BMC Medical Informatics and Decision Making 2009;9:24.

[16] J. Farhan, S. Al-Jummaa, A. A. Alrajhi, et al. Documentation and coding of medical records in a tertiary care centre: A pilot study. Ann Saudi Med. 2005; 25(1):46-9.

[17] Mahmood K, Shakeel S, Saeedi I, et al. Audit of medical record documentation of patients admitted to a medical unit in a teaching hospital NWFP Pakistan. JPMI 2007 21(2):113-116.

[18] C. Paul, M. P. LaRosa, S. M. Gorden. Use of computer-based records, completeness of documentation and appropriateness of documented clinical decisions. J Am Med Inform Assoc. 1999;6(3):245-251.

[19] W. C. Morris, D. T. Heinze, Warner HR, et al. Assessing the accuracy of automated coding system in Emergency Medicine. 1067-5027/001\$5.00 C) 2000 AMIA, Inc.595-599. 
[20] L. Lorenzoni, R. D. Cas, U. L. Aparo. The quality of abstracting medical information from the medical record: the impact of training programmes. Int $\mathrm{J}$ Qual Health Care. 1999;11(3):209-213. doi: 10.1093/intqhe/11.3.209.

[21] S. V. S. Pakhomov, J. D. Buntrock, C. G. Chute. Automating the assignment of diagnosis codes to patient encounters using example-based and machine learning techniques. J Am Med Inform Assoc. 2006;13(5):516-525. doi: 10.1197/jamia.M2077.

[22] J. A. Langlois, J. S. Buechner, E. A. O'Connor, et al. Improving the e-coding of hospitalizations for injury: Do hospital records contain adequate documentation? Am J of Public Health. 1995;85(9):1261-1265. PMCID: PMC1615600.

[23] R. L. Walker, D. A. Hennessy, H. Johansen, C. Sambell, L. Lix, $\mathrm{H}$. Quan. Implementation of ICD-10 in Canada: how has it impacted coded hospital discharge data. BMC Health Services Research. 2012;12:149.

[24] M. Topaz, L. Shafran-Topaz, K. H. Bowles. ICD-9 to ICD-10: Evolution, revolution, and current debates in the United States. Perspectives in Health Information Management, Spring 2013.

[25] L. Jones. The quality of clinical documentation and subsequent effect on DRG assignment: A report on the findings of the DRG documentation study: Casemix development program. Commonwealth Department of Health, Housing and Community Services, Canberra, 1993. Available at: www.wpro.who.int/publications/docs Accessed on: 9th June 2012.

[26] J. H. Garvin, V. J. M. Watzlaf. Current coding competency compared to the projected. Perspect Health Inf Manag. 2004; $1: 2$.

[27] J. Ashley (1990/91) The International Classification of Diseases: the structure and content of the tenth revision. Health Trends. 1991; 22(4):135-137.

[28] C. Rooney, C. Griffiths, L. Cook. The implementation of ICD10 for cause of death coding: some preliminary results from the bridge coding study. Health Statistics Quarterly. 2002;13:31-41.

[29] B. Fox, J. Sheehan. Openness and exactness: mitigating fraud vulnerabilities in the age of EHRs and ICD-10, 2012. Available at: http://69.59.162.218/HIMSS2012/Venetian\%20Sands\%20Exp o\%20Center/2.21.12_Tue/Casanova\%20502/Tue_1530/SHIF T5_Bill_Fox_Casanova\%20502/SHIFT5_Fox.pdf Accessed August 20, 2012.

[30] F. Upton, P. Sessions. Implementation of ICD-10 in USA: the most recent coding system to be used by healthcare providers for reimbursement and other functions. United States of American House Energy and Commerce Committee and House Rules Committee. Available at: www.energycommerce.house.gov/press-release/housechairmen-upton-sessions-statement-icd-10. Accessed December 16, 2014.

[31] I. T. Adeleke, S. A. Erinle, A. M. Ndana, T. C. Anamah, O. A. Ogundele, D. Aliyu. Health information technology in Nigeria: Stakeholders' perspectives of nationwide implementations and meaningful use of the emerging technology in the most populous black nation. American Journal of Health Research. Special Issue: Health information technology in developing nations: challenges and prospects health information technology. 2014;3(1-1):17-24. 10.11648/j.ajhr.s.2015030101.13.
[32] I. T. Adeleke, A. H. Lawal, R. A. Adio, A. A. Adebisi. Information technology skills and training needs of health information management professionals in Nigeria: a nationwide study. Health Information Management Journal, 2014. doi.org/10.12826/18333575.2014.0002.Adeleke.

[33] C. I. F. Rooney, S. K. Smith. Health Statistics Quarterly. 2000;08:41-50.

[34] M. Rorsch. Computer-assisted coding: emerging technology today, primary coding technology tomorrow, 2012. Available at: Optum www.optuminsight.com Accessed on: December 15, 2014.

[35] W. C. Moris, D. T. Heinze, H. R. Warner, et al. Assessing the accuracy of an automated coding system in emergency medicine. Proc AMIA Symp. 2000:595-9

[36] C. Bouchet, F. Empereur, F. Kohler. Evaluating a computerized tool for coding patient information. Proc AMIA Symp. 1998:185-9.

[37] S. S. Lloyd, E. Layman. The effects of automated encoders on coding accuracy and coding speed. Top Health Inf Manage. 1997;17(3):72-9.

[38] N. F. Khan, S. E. Harrison, P. W. Rose. Validity of diagnostic coding within the General Practice Research Database: a systematic review. Br J Gen Pract. 2010;60(572):e128-e136.

[39] J. Arthur, R. Nair. Increasing the accuracy of operative coding. Ann R Coll Surg Engl 2004; 86:210-212.

[40] I. T. Adeleke. Knowledge, attitude and practice of clinical coding among HIM professionals at Federal Medical Centre, Bida. B.Sc. project submitted to Houdegbe North Amrican University, Cotonou, Republic of Benin, 2012.

[41] O. O. Adepoju. Knowledge and practice of clinical coding among healthcare providers in three Nigerian tertiary hospitals. B.Sc. project submitted to Houdegbe North Amrican University, Cotonou, Republic of Benin, 2013.

[42] C. Rao, D. Bradshaw, C. D. Mathers. Improving death registration and statistics in developing countries. Lessons from sub-saharan Africa. SAJDem. 9(2):81-99.

[43] J. Cunningham, D. Williamson, K. M. Robinson, R. Carroll, R Buchanan, L. Paul. The quality of medical record documentation and External cause of fall injury coding in a tertiary teaching hospital. Health Information Management Journal. 2014;43(1):6-15. ISSN 1833-3583 (Print) ISSN 18333575 (Online).

[44] K. McKenzie, S. Walker, C. Dixon-Lee, et al. Clinical coding internationally: a comparison of the coding workforce in Australia, America, Canada and England. Available at: www.eprints.qut.edu.au Accessed on July 20, 2012.

[45] F. J. Rodriguez-Vera, Y. Marin, A. Sanchez, et al. Illegible handwriting in medical records. J R Soc. Med. 2002; 95(11): 545-546.

[46] S. Kumar, K. M. Thomas KM. Development of a hospital based menu driven clinician coding tool to implement quality reimbursement process in the U.S.--a cardiologist's diagnoses as an illustration. Technol Health Care 2011; 19(6):423-34.

[47] S. Santos, G. Murphy, K. Baxter, K. M. Robinson. Organisational factors affecting the quality of hospital clinical coding. Health Information Management Journal. 
2008;37(1):25-37. ISSN 1833-3583 (Print) ISSN 1833-3575 (Online).

[48] A. Arends-Marquez, N. Knight, D. Thomas-Flowers. ICD10 's impact reaches far beyond coding: examining the new code sets' revenue cycle implications. Journal of AHIMA. 2014;85(11):74-76. Available at: www.library.ahima.org/xpedio/groups/public/documents/ahim a/bok1_050783.hcsp?dDocName=bok1_050783. Accessed on December 16, 2014.
[49] World Health Organization. Classification of health workers: Mapping occupations to the international standard classification. World Health Organization, Geneva. Available at www.who.int/hrh/statistics/workforce_statistics. Accessed on: $28^{\text {th }}$ May 2012.

[50] M. Leppert. Coder productivity in ICD-10-PCS. ICD-10 Trainer. 2012. http://blogs.hcpro.com/icd-10/2012/10/coderproductivity-in-icd-10-pcs/. 